\title{
Optimal Placement of Thyristor Controlled Series Compensator (TCSC) on Nigerian 330kV Transmission Grid to Minimize Real Power Losses
}

\author{
M. N. Nwohu, A. Isah, A. U. Usman, A. A. Sadiq \\ Department of Electrical/Electronics Engineering \\ Federal University of Technology, Minna
}

\begin{abstract}
This paper explores the use of Flexible Alternating Current Transmission System (FACTS) devices to improve the power system security and availability through an optimal location and parameter settings of FACTS devices. The Nigerian transmission grid was modeled and simulated in PSAT environment as a 35-bus system. Thyristor Control Series Compensator (TCSC) is among the FACTS devices that is capable of reducing transmission line losses and increase the voltage profile of the buses. Here, Genetic Algorithm (GA) optimization technique has been deployed as an effective method of placing TCSC on the Nigerian 330kV Grid System, to control power flow and improve bus voltages. Results obtained show reduction of overall active power losses from the initial $2.1 \%$ to $1.5 \%$.
\end{abstract}

Keywords: FACTS devices, TCSC, Transmission grid, PSAT, Optimal Power Flow, Genetic Algorithm and Optimization techniques.

\section{INTRODUCTION}

The Nigerian grid system that transverse the country is now owned and managed by the Transmission Company of Nigeria (TCN). In order to satisfy the increased electrical power demand and trades due to increased unplanned exchange as the market participants transfer energy between various points, transmission lines are often driven close to or even beyond thermal, voltage and stability limits[1]. Since the current transmission networks were not originally planned for trading in a competitive market, this task might violate the capacity of what the transmission line can take. This can lead to fluctuations in power flows through the transmission lines with resulting effects as increase power loss especially in congested lines as well as cascading outages that consequently result in system collapse [2]. The current average available transmission capacity on the $330 / 132 \mathrm{kV}$ transformer is 7 , 364MVA with $95.2 \%$ of installed capacity with average transmission loss of $8.5 \%$ [11].

A flexible AC Transmission System (FACTS) device especially the TCSC due to its power regulation has the capability to relieve transmission congestion and allows better utilization of the existing grid infrastructure, and along other benefits like maintaining a healthy system [4].

It has become a challenge to coordinate and operate at an effective, reliable and low power loss environment to meet the consumer need.

\section{Loss MANAgement in CONGESTED LiNES BY METHOD OF GENERATION RESCHEDULING AND LOAD SHEDDING}

This method is considered as one of the ways of reducing transmission line losses and voltage stability enhancement. In Generation Rescheduling and Load Shedding, some line overloads can be alleviated by generation rescheduling alone [5]. The computational expenses can be minimized by attempting generation rescheduling during the initial overload alleviation pass followed by load shedding in the subsequent passes. When all available controls are unable to maintain the security of the system operation during a disturbance or contingency, optimal load shedding will be used as the last resort to isolate some buses from power supply in order to avert total collapse of the system or blackout [6]. This approach leads to low customer satisfaction as the electricity will not be available when needed. 


\section{The Nigerian 330KV Transmission Grid SySTEM}

The $330 \mathrm{kV}$ voltage level considered as extra- high voltage in Nigeria and referred to as the Nigerian grid system. The Nigerian grid in Power System Analysis Toolbox (PSAT) software simulated in MATLAB environment shows the grid consists of thirty five (35) buses, twenty six (26) transmission lines and nine (9) working generating stations as at the time of this paper. The Nigerian grid is made up of approximately $5,523.7 \mathrm{Km}$ of $330 \mathrm{kV}$ transmission lines and thirty two $330 / 132 \mathrm{kV}$ substations with total installed transformer capacity of 7,688MVA while on the average, the available capacity on the 330/132kV is 7,364MVA [8]. The bus at Egbin Generating Station is chosen as the slack bus. The Table 3.1 shows the installed capacity of the nine power generating stations and their fuel used.

Table3.1. Electricity Power Stations of the Nigerian Power Grid

\begin{tabular}{|l|l|l|l|l|l|l|l|l|l|}
\hline POWER STATIONS & Egbin & Sapele & Afam & Delta & Kainji & Shiroro & Jebba & Ihovbor & Geregu \\
\hline FUEL/ TYPE USED & Gas & Thermal & Thermal & Thermal & Hydro & Hydro & Hydro & Thermal & Gas \\
\hline $\begin{array}{l}\text { INSTALLED CAPACITY } \\
\text { (MW) }\end{array}$ & 1320 & 1020 & 969.6 & 912 & 760 & 600 & 578.4 & 451 & 414 \\
\hline
\end{tabular}

Source: $P H C N(2010)$.

\section{Formulation of ObJective Function for Optimal Placement of TCSC}

Optimal placement of TCSC on a line in the PSAT simulation software environment aimed at achieving least overall system real power loss, $P \operatorname{loss}(M W)$.

The objective function for loss minimization is given by;

$$
\begin{aligned}
& \min \sum_{i}^{n} \text { Ploss } \\
& \text { Ploss }=\sum_{i=1}^{n}(P g-P d)
\end{aligned}
$$

Where $P g$ and $P d$ are total real power injected and total real power demanded respectively.

The objective function for line power flow control is given by;

$$
\max \sum_{i=1}^{j} \text { Xeff }
$$

Where,

$$
\begin{aligned}
& \text { Xeff }=(1+K) * \text { Xline } \\
& K=\frac{X t \csc }{X \text { line }}
\end{aligned}
$$

$X t \csc =\frac{X c * X l}{X l-X c}$

$X e f f=$ Effective series transmission impedance in p.u.;

$X t \mathrm{csc}=$ Equivalent reactance of TCSC p.u.;

Xline $=$ Equivalent reactance of transmission line p.u.;

$X c=$ Effective reactance of the capacitor p.u.;

$X l=$ Effective reactance of the inductor p.u.;

\subsection{Optimization Technique - Genetic Algorithms (GA)}

GA is described as new radical approach to optimization because of its independence on knowing the derivatives of the objective function. Genetic Algorithms (GA) is good for power system 
optimization, which offers significant advantages and better optimization performances [3]. The basic concept in GA is from the Darwin's postulation of survival of the fittest, which implies only the best individuals will be selected based on defined fitness level to participate with their genetic parameters in the next generation [9].

G.A only works with coding of the parameters set, not the parameters themselves. For a given population (candidate buses), overall system real power loss will be minimized, which implies that the line which results in least real power loss is taken ideal for better location of TCSC. The G.A is illustrated in block form as shown in Figure 4.1.

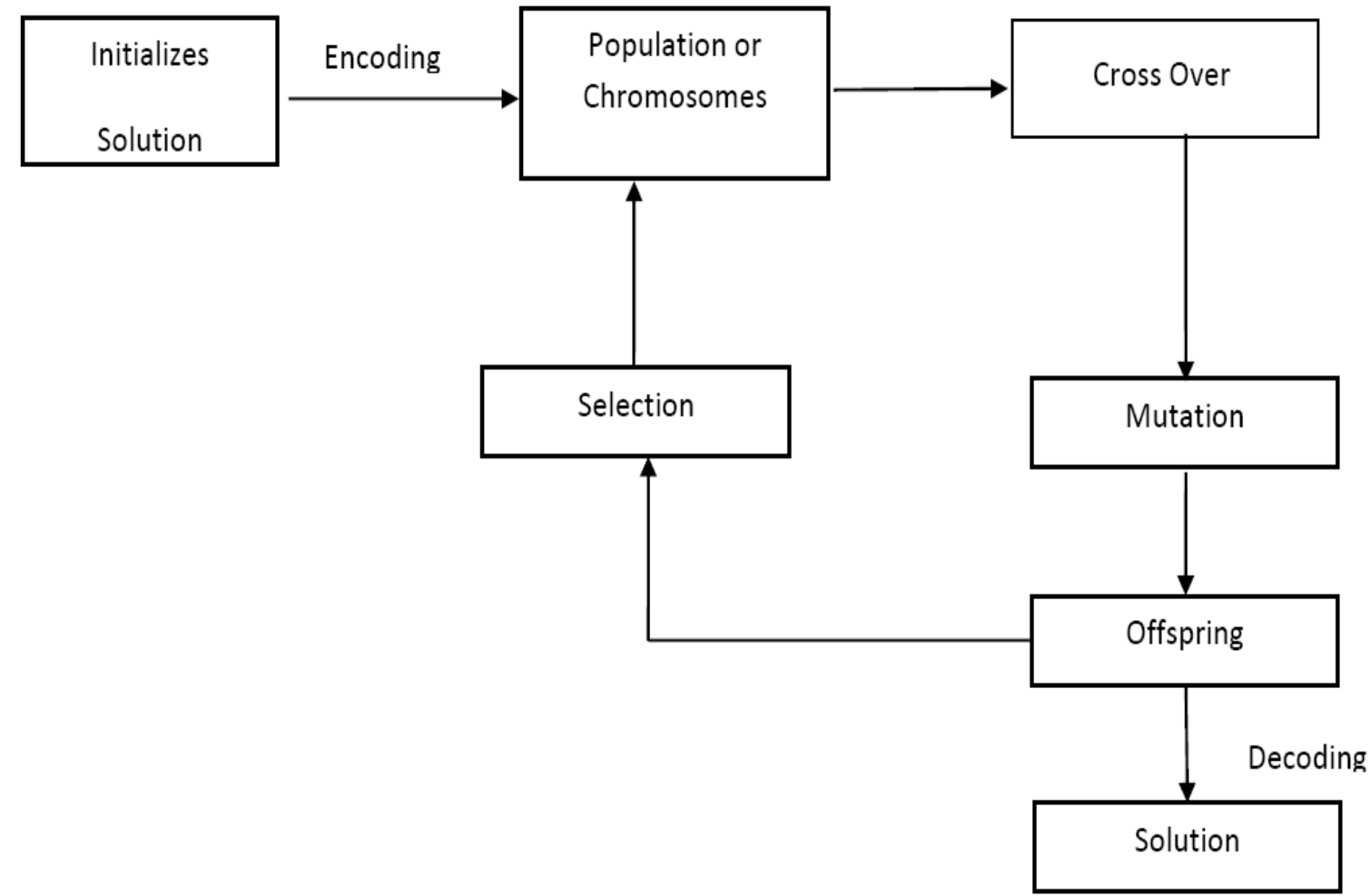

Figure4.1. The block diagram showing the General Structure of GA-Evolution.

Therefore the fitness function can be expressed as:

$$
\max f(X c, X l)=1+((X c * X l) \div(X l-X c))
$$

Subjected to:

$$
\text { Ploss }^{1} \leq \text { Ploss }^{0}
$$

$(0.1 \leq X c \leq 0.3) p u$ and $(-0.2 \leq X l \leq 0.2) p u$

Where, Ploss ${ }^{1}$ and Ploss $^{0}$ are total power losses before and after location of TCSC in the Grid respectively.

For effective operation, the basic algorithms steps as follow;

Step1: initialize a population (randomly done) and set the generation counter to zero;

Step2: calculate the fitness of each member of the population;

Step3: select parents using some fitness bias formulae (objective function);

Step4: crossover the parents to create new offspring;

Step5: mutate this new offspring;

Step6: replace the lesser fit members with the offspring; 
Step7: done when desired generation counter reached, else;

Step8: increment the generations counter and go to step 2.

\section{TCSC Model For Power Flow ConTrol}

The real $P i j$ and reactive $Q i j$ power flows of the line connected between bus- $i$ and bus-j having series impedance can be written as,

$$
\begin{aligned}
& P i j=V^{2} i G i j-V i V j[G i j \cos (\partial) i j+B i j \sin (\partial) i j] \\
& Q i j=-V^{2} i(B i j+B s h)-V i V j[G i j \sin (\partial) i j-B i j \cos (\partial) i j]
\end{aligned}
$$

Similarly for $P j i$ and $Q j i$,

$$
\begin{aligned}
& P i j=V^{2} j G i j-V i V j[G i j \cos (\partial) i j-B i j \sin (\partial) i j] \\
& Q i j=-V^{2} j(B i j+B s h)+V i V j[G i j \sin (\partial) i j+B i j \cos (\partial) i j]
\end{aligned}
$$

Where, $V i$ and $V j$ are voltage magnitudes at bus- $i$ and bus- $j$ respectively;

$\partial i j$ - Voltage angle difference between bus- $i$ and bus- $j$;

Gij- Conductance between bus- $i$ and bus-j ( $p \boldsymbol{u}$ );

Bij-Susceptance between bus- $i$ and bus-j ( $p u$ ).

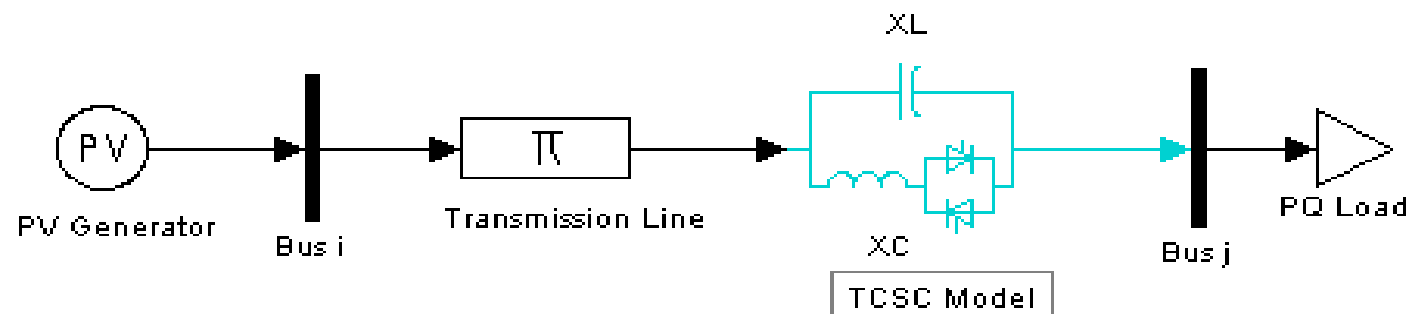

Figure3.3. Transmission Line with TCSC

Figure 3.3 shows the TCSC model inserted into the transmission line to give the overall effective line impedance during power flow.

The conductance and susceptance without FACTS controller in the network are given by;

$$
\begin{aligned}
& G i j=\frac{R i j}{R^{2} i j+X^{2} e f f} \\
& B i j=\frac{-X e f f}{R^{2} i j+X^{2} e f f}
\end{aligned}
$$

Where Xeff $=$ Xline

With FACTS Controller in the network;

Xeff $=(1+K) *$ Xline

At steady state operation, TCSC is considered as an additional reactance XtcsC which its value can be adjusted to desired controlled scheme so that more or less power flows can be injected into the network depending on degree of compensation. For this simulation, the values of $X l$ and $X c$ used are bounded by upper and lower limits $-0.2 / 0.2$ p.u. and $0.1 / 0.3$ p.u respectively. 


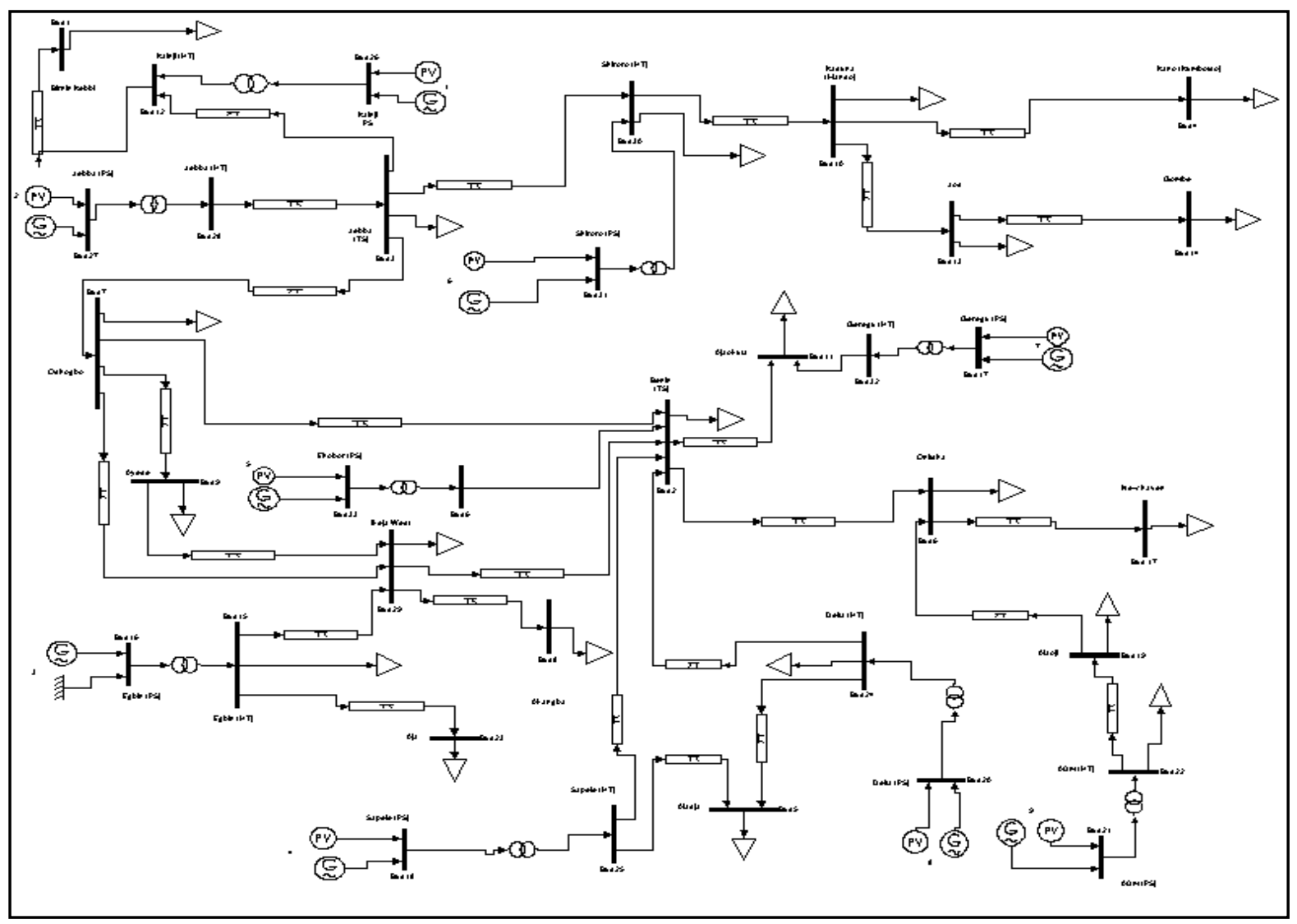

Figure3.4. PSAT model of Nigeria Power Grid without TCSC

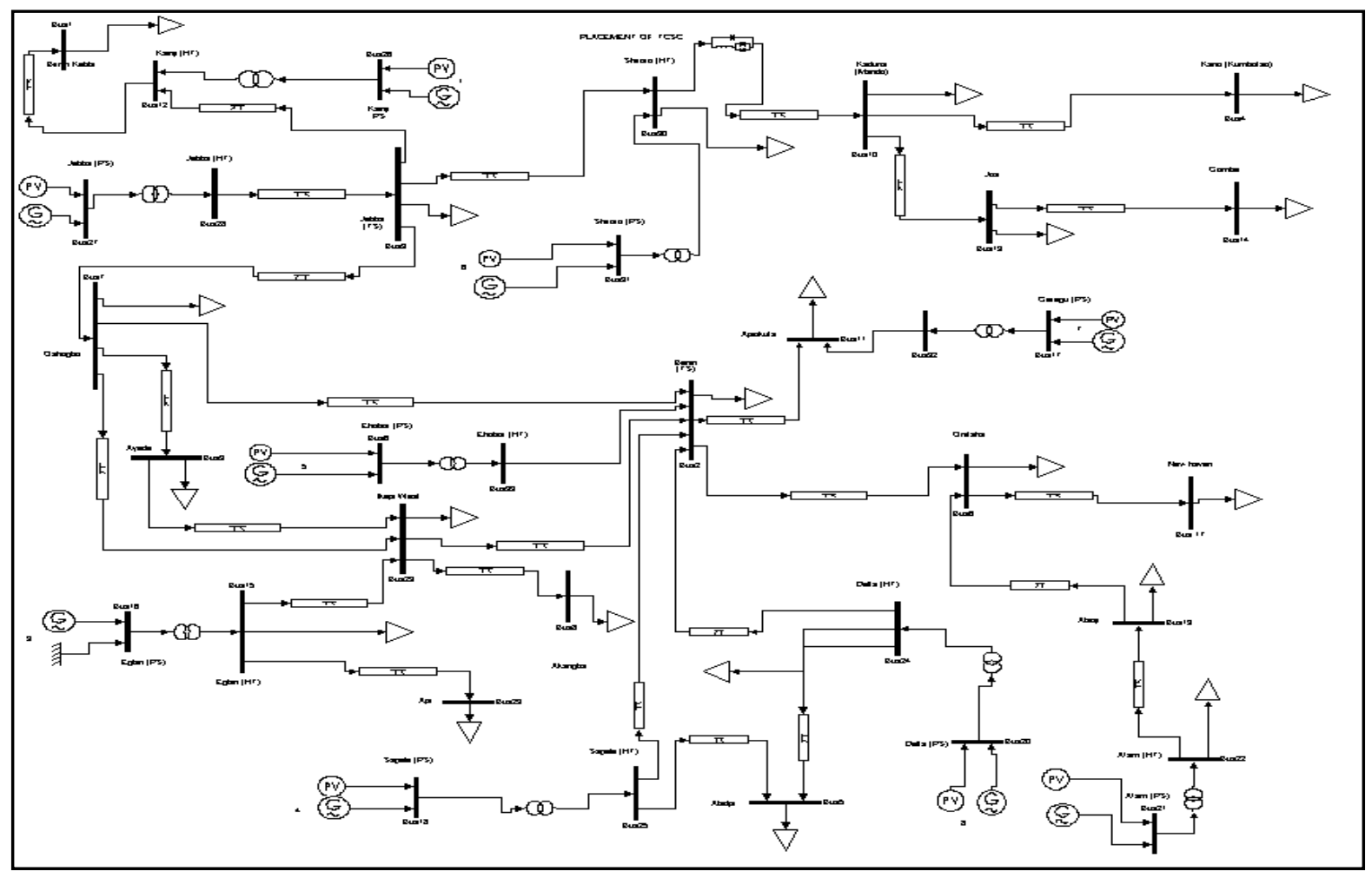

Figure3.5. PSAT model of Nigeria Power Grid with TCSC 
M. N. Nwohu. et al.

\section{RESUlTS AND DISCUSSION}

Table 6.1 shows the candidate lines for optimal placement of TCSC in Transmission Grid

Table 6.1. TCSC placement values for candidate buses.

\begin{tabular}{|l|l|l|}
\hline & FROM CANDIDATE BUSES & FITNESS FUNCTION LEVEL \\
\hline 2 & Bus1_Birnin Kebbi & 0.1156 \\
\hline 4 & Bus3_Jebba (TS) & 0.0711 \\
\hline 6 & Bus7_Oshogbo & 0.3848 \\
\hline 8 & Bus11_Ajoakuta & -0.1000 \\
\hline 10 & Bus14_Gombe & 0.6818 \\
\hline 12 & Bus10_Kaduna (Mando) & 0.1950 \\
\hline 14 & Bus30_Shirror (HT) & 0.9735 \\
\hline 16 & Bus27_Jebba (TS) & 0.3354 \\
\hline 18 & Bus19_Alaoji & 0.1950 \\
\hline 20 & Bus17_New Haven & 0.5599 \\
\hline 22 & Bus32_Geregu (PS) & -0.0322 \\
\hline 24 & Bus13_Jos & 0.2951 \\
\hline 26 & Bus25_Sapele (HT) & 0.1921 \\
\hline 28 & Bus4_Kano & 0.3171 \\
\hline 30 & Bus22_Afam(HT) & -0.3354 \\
\hline
\end{tabular}

Table 6.2 shows the voltage profiles of the buses before and after placing TCSC with percentage of improvement.

Table 6.2. Voltage Profiles of the Buses before and after placing TCSC.

\begin{tabular}{|c|c|c|c|c|}
\hline \multirow{2}{*}{ BUSES } & \multicolumn{2}{|c|}{ VOLTAGE PROFILE OF BUSES (KV) } & \multirow{2}{*}{$\begin{array}{l}\text { IMPROVEMENT } \\
\text { OF VOLTAGE }\end{array}$} \\
\cline { 3 - 4 } & & Before TCSC & After TCSC & 0.22 \\
\hline 2 & Benin(TS)_2 & 334.50 & 335.23 & 8.42 \\
\hline 4 & Kano_4 & 319.26 & 346.15 & 0.20 \\
\hline 6 & Akangba_8 & 307.71 & 308.34 & 0.23 \\
\hline 8 & Ayede_9 & 315.30 & 316.03 & 4.50 \\
\hline 10 & Kaduna_10 & 333.28 & 348.42 & 5.10 \\
\hline 12 & Jos_13 & 341.83 & 359.20 & 5.40 \\
\hline 14 & Gombe_14 & 344.96 & 363.46 & 0.12 \\
\hline 16 & New Haven_17 & 323.73 & 324.13 & 0.08 \\
\hline 18 & Delta(HT)_24 & 330.77 & 331.04 & 1.36 \\
\hline 20 & Shirror(HT)30 & 341.66 & 346.30 & \\
\hline
\end{tabular}

Table 6.3 shows the lines Real Power Losses before and after placing TCSC and percentage loss reduction.

Table 6.3. Real Power Loss between buses before and after placing TCSC

\begin{tabular}{|l|l|l|l|l|}
\hline \multirow{2}{*}{} & \multirow{2}{*}{ From Bus to Bus } & \multicolumn{2}{|l|}{ REAL POWER LOSS (MW) } & \% LOSS \\
\cline { 3 - 4 } & & Before TCSC & After TCSC & REDUCTION \\
\hline 2 & Jebba(TS)- Kano & 1.1511 & 1.0572 & 8.20 \\
\hline 5 & Shirror(HT)- Kaduna & 9.9716 & 2.5597 & 74.0 \\
\hline 6 & Kaduna-Kano & 3.3592 & 0.3745 & 88.8 \\
\hline 9 & Benin(TS)-Ajoakuta & 4.8182 & 0.94502 & 80.4 \\
\hline 13 & Jebba(TS)-Oshogbo & 1.7654 & 1.524 & 13.6 \\
\hline 14 & Afam(HT)- Alaoji & 0.18706 & 0.16922 & 9.50 \\
\hline 19 & Ayede- Ikeja west & 0.55154 & 0.50755 & 8.00 \\
\hline 25 & Ikeja west-Egbin(HT) & 15.1912 & 13.8329 & 8.90 \\
\hline 16 & Sapele (HT)-Benin(TS) & 0.82758 & 0.80168 & 3.1 \\
\hline
\end{tabular}




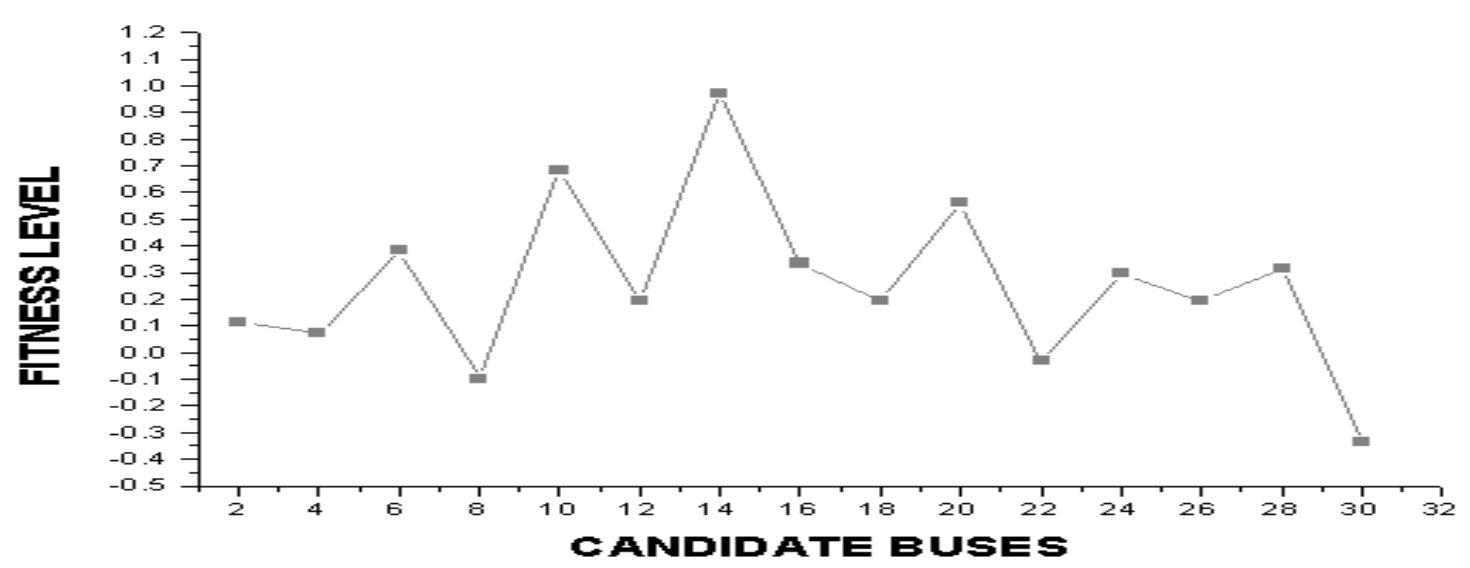

Figure6.1. TCSC placement of candidate bus of Nigeria Grid

Figure 6.1 depicts the fitness level values among the candidate buses of the Transmission Grid system, where candidate bus 15 has the highest expected value of fitness function compared to others. The bus (Shiroro HT_30) is therefore considered most suitable for optimal placement of TCSC to achieve the objective function.

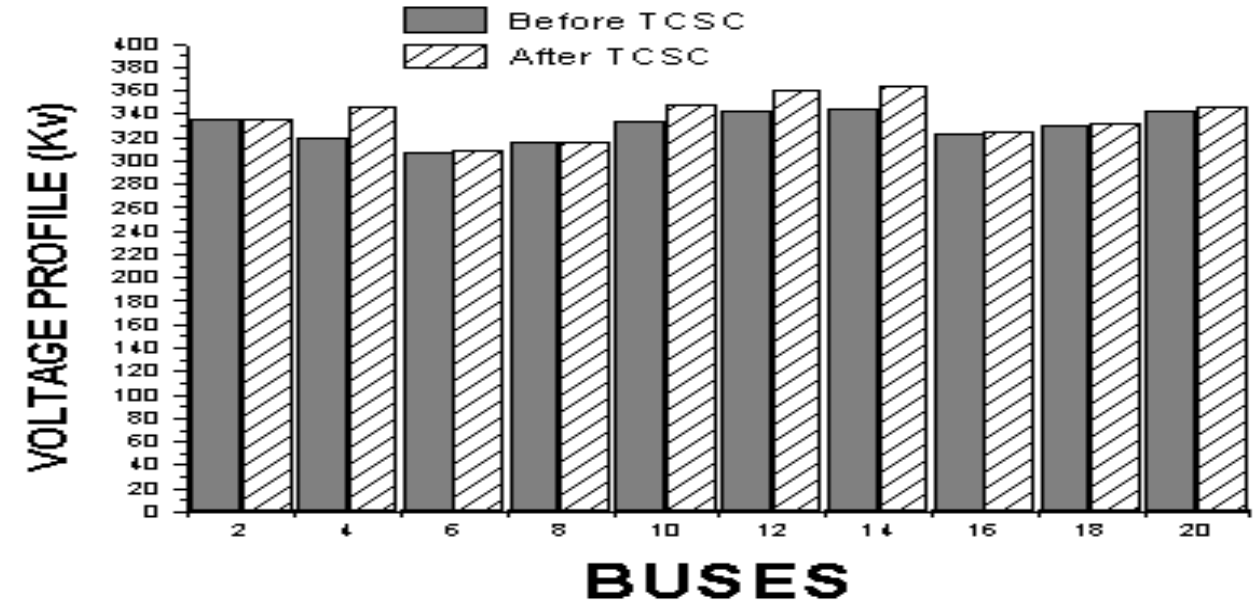

Figure6.2. Voltage Profiles of the Buses

Figure 6.2 depicted the voltage profiles of the buses before and after placement of TCSC. From Table 6.2, it is seen that TCSC improved the voltage profiles, where the bus 4 (Kano) voltage increased by $8.42 \%$ after TCSC placed in the Grid network.

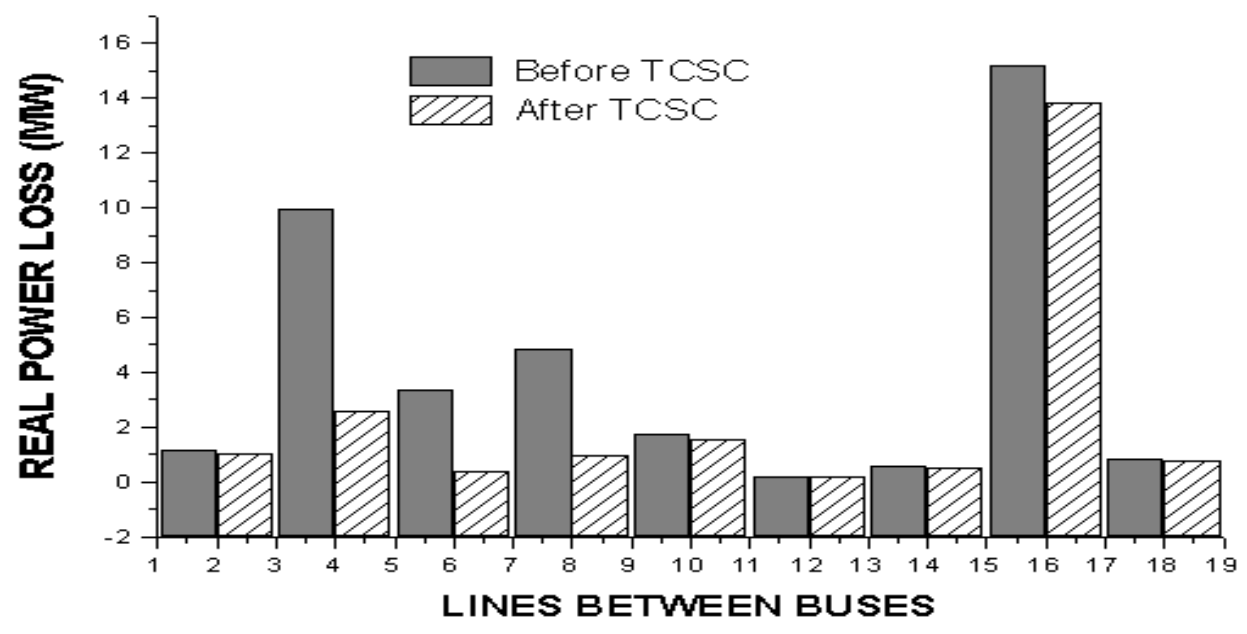

Figure6.3. Real Power Losses in the Transmission Lines 
The figure 4.3 shows the real losses in Nigeria $330 \mathrm{Kv}$ transmission lines before and after optimal placement of TCSC in the Grid respectively. The following lines before TCSC (line 5 between bus30_Shiroro HT and bus10_Kaduna, line 6 between bus10_Kaduna and bus4_Kano, line 9 between bus2_Benin(TS) and bus11_Ajoakuta) experienced heavy power losses due to high power flow beyond the capability of the lines. After placement, the TCSC inject more inductive reactance into those lines to discourage power flow and avoid forming loop flow since power flows more where there is less load.

The result of simulation indicates that the total generation and load of $330 \mathrm{kV}$ Nigeria Grid are approximately 2,890.44 MW and 2,830.10 MW respectively. The total losses before TCSC is approximately $60.34 \mathrm{MW}$ (about $2.1 \%$ of generation), while with TCSC is approximately $45.35 \mathrm{MW}$ (about $1.5 \%$ of generation).

Power saved by TCSC $=$ power loss before TCSC - power loss after TCSC

$$
\begin{aligned}
& =60.3439-45.3591 \\
& =15 \mathrm{MW} .
\end{aligned}
$$

\section{CONCLUSION}

The work indicates that with TCSC installed on the Nigerian $330 \mathrm{kV}$ grid system, power loss in the transmission lines reduced to $1.5 \%$ as against the initial $2.1 \%$ when TCSC is not installed. The use of genetic algorithm was employed to determine the location of TCSC on the network at the appropriate line where its effectiveness is prominently observed on the network.

\section{REFERENCES}

[1] Leadership Newspaper, "Facts and Way-forward in Deregulation of Power Sector in Nigeria", Current Issue in Power Sector, pp23-24 November 23, 2012, www.nigeriannews.com

[2] D.A Panasetsky, student Member IEEE and N.I Voropai, "A Distributed Control of FACTS Devices against Line Overloading" International Conferences on Power System Technology, pp.1-6, 2010

[3] NazaninHosseinipor, Syed M. HNabavi, "Optimal Locating and Sizing of TCSC using Genetic Algorithm for Congestion Management in Deregulated Power Market". International Conference on Environment and Electrical Engineering, pp.136-139, May 2010.

[4] Nwohu M.N, “An Overview of Flexible AC Transmission Systems Technology" Department of Electrical/Computer Engineering, FUT Minna, pp.1-8, 2011.

[5] Selvi, K. Meena, T. Ramaraj, N. "A Generation Rescheduling Method to Alleviate Line Overhead using PSO” Institute of Engineers, 2007, vol;88, pp.10-13, January 27.

[6] A Shandila, H.Gupta and J. Sharma, "Methods for Generation Rescheduling and Load Shedding to Alleviate Line Overloads using Local Optimization." IEEE Proceedings, vol. 140, No 5, September 1993, pp. 337-342.

[7] Labo H.S (2010) Current Status and Future Outlook of the Transmission Network. Paper presented at the investors forum for the Privatization of the PHCN Successor Company, January $18-19^{\text {th }}$

[8] Eseoso O. and Odiase F.O (2012) Efficiency Improvement of Nigeria 330KV Network using (FACTS) Devices. International Journal of Advances in Engineering \& Technology. Vol.4 Issue1, 26-41

[9] Koza J. (1992). Genetic Programming: On the programming of computers by means of natural selection. Masschusetts: MIT Press, pp 2-10. 


\section{AUTHORS' BIOGRAPHY}

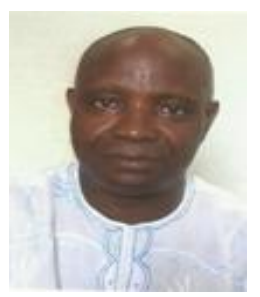

Engr. Dr. M. N. Nwohu, is an Associate Professor in Electrical Power Engineering. He received his bachelor of Engineering (B.Eng.) in Power Systems Engineering Technology from Federal University of Technology, Owerri, Nigeria, in 1988. He got his Masters degree in Power and Machines from University of Benin, Nigeria in 1994. In 2007, he badged on his Doctor of Philosophy (PhD) Degree in Power Systems Engineering from Abubakar Tafawa Balewa University, Bauchi, Nigeria. His research interest includes Power System Analysis, Power System Stability and Control, Application of FACTS devices to Power Systems, System Simulation, Power Quality, and Numerical Analysis. He was Head of Department of Electrical and Computer Engineering, Federal University of Technology, Minna in 2002/2003 session and Head of Department of Computer Engineering of same University in 2011/2012 session.

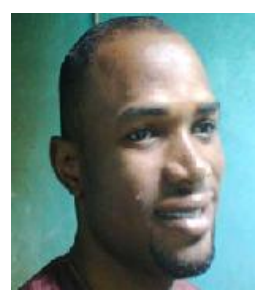

Mr. Isah, Abubakar, holds BEng degree in Electrical and Computer Engineering from Federal University of Technology, Minna and was a Postgraduate student in the Department of Electrical and Electronics Engineering, Federal University of Technology, Minna.

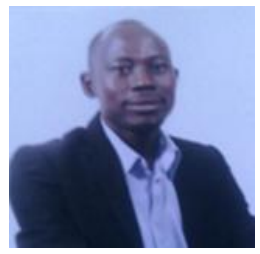

Dr. Usman A. Usman, is a Senior Lecturer with the Department of Electrical and Electronics Engineering, Federal University of Technology, Minna, Nigeria. He obtained his B.Eng. in Electrical \& Computer Engineering from the same University in 1998. He acquired M.Sc. in Electronics and Communication Engineering from University of Lagos, Nigeria and $\mathrm{PhD}$ in Communication Engineering from Abubakar Tafawa Balewa University, Bauchi Nigeria in 2002 and 2014 respectively. He is currently the Departmental Post graduate coordinator. He has teaching experience in the area of mobile radio propagation modeling, wireless communication system, wireless network resource utilization, QoS in wireless networks, and digital electronics. His research interest includes radio propagation modelling, antenna and RF design, indoor and outdoor wireless communication and application of Artificial Intelligent techniques in Electrical Engineering. He has published several papers in national/international journal and conferences.

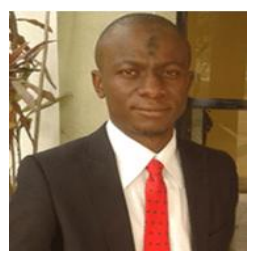

Engr. A. A. Sadiq, received the BEng degree in Electrical and Computer Engineering from Federal University of Technology, Minna in 2008 and MEng in Electric Power and Machine in 2013 from same University. He is currently a Lecturer with the department of Electrical and Electronics Engineering, Federal university of Technology, Minna. His Research interest is in power systems planning and operations with specifics in ATC enhancement, deployment of FACTS and DGs. He has authored some publications in International journals and conference proceedings. 